\title{
A levels of endogenous gonadal hormones and their relationship with selected coronary artery disease risk factors among young women post myocardial infarction
}

\author{
Urszula Ablewska1, Krzysztof Jankowski² ${ }^{\bowtie}$, Ewa Rzewuska², Danuta Liszewska-Pfejfer² and \\ Tomasz Hryniewiecki ${ }^{1}$
}

1Department of Acquired Heart Valve Diseases, National Institute of Cardiology, Warszawa, Poland; ${ }^{2}$ Department of Internal Medicine and Cardiology, Medical University of Warsaw, Warszawa, Poland

In recent decades a significant raise in the incidence of myocardial infarction among young women has been recorded. It is presumed that, apart from the classical risk factors, other reasons exist for premature atherosclerosis in young women, related to the homeostasis of gonadal hormones. The aim of the study was to analyze the levels of gonadal hormones (estradiol, progesterone, follicle-stimulating hormone, luteinizing hormone, testosterone and dehydroepiandrosterone) measured in the luteal phase, in 65 normally menstruating women post myocardial infarction (MI) and to investigate a possible relationship between the hormone profile and selected coronary artery disease (CAD) risk factors. The levels of gonadal hormones: estradiol, progesterone, folliclestimulating hormone, luteinizing hormone, testosterone and dehydroepiandrosterone were measured in the luteal phase. All examined women had normal mean levels of gonadal hormones. In the post MI patients leading a sedentary life style, a significantly lower mean progesterone concentration was observed $(16.29 \pm 9.11$ versus $29.43 \pm 21.14 \mathrm{nmol} / \mathrm{l}, p<0.05$ ) and significantly higher mean testosterone concentration (2.34 0.98 versus $1.76 \pm 1.09 \mathrm{nmol} / \mathrm{l}, p<0.05)$ when compared to patients from the same group, but leading a more active life. In obese post MI women $\left(B M I \geq 30 \mathrm{~kg} / \mathrm{m}^{2}\right)$ a lower mean concentration of progesterone was detected $(18.02 \pm 8.12$ versus $26.16 \pm 14.72 \mathrm{nmol} / \mathrm{l}, p<0.05)$, than in slimmer patients from the same group. In post MI women with a positive family history for CAD, a significantly higher mean concentration of testosterone was detected $(2.31 \pm 1.22$ versus $1.67 \pm 0.74 \mathrm{nmol} / \mathrm{l}, p<0.05)$ than in patients with no family history. The results suggest a correlation between levels of gonadal hormones and classical CAD risk factors.

Keywords: gonadal hormones, young women, risk factors, myocardial infarction

Received: 08 March, 2011; revised: 23 August, 2011; accepted: 02 September, 2011; available on-line: 13 September, 2011

\section{INTRODUCTION}

Although premenopausal women are less prone to developing coronary artery disease (CAD) compared to men of the same age, cardiovascular diseases are the cause of $24.8 \%$ deaths among women aged 25-54 (Broda et al., 2000).
In the last 2-3 decades in Western countries a significant raise in the incidence of myocardial infarction (MI) among young women has been recorded (Doughty et al., 2002; Arciero et al., 2004; Ergin et al., 2004).

It is presumed that, apart from the classical risk factors such as arterial hypertension, hypercholesterolemia, diabetes mellitus, smoking, obesity, genetic predisposition, also other factors are responsible for premature atherosclerosis in young women, namely unbalanced levels of gonadal hormones (Smielak-Korombel et al., 1986; Ostadal et al., 2009).

So far the role of endogenous gonadal hormones in pathogenesis of MI in young women and their relationship with classical CAD risk factors is not very well established.

The aim of the project was to analyze the levels of gonadal hormones in normally menstruating women post $\mathrm{MI}$ and to investigate a possible relationship between the hormone profile and selected CAD risk factors.

\section{MATERIAL AND METHODS}

The study included 65 regularly menstruating women aged 33-48 years (mean age $43 \pm 5.4$ years), that had MI 6-24 months earlier - group I. Group II consisted of 30 healthy volunteering women of similar age (mean $42 \pm 4.8$ years). The inclusion criterion was the presence of regular menstrual cycles. Women using oral contraceptives or other hormonal treatment were excluded from the study. Also women with diabetes, connective tissue diseases, kidney failure or thyroid diseases were excluded.

The study was approved by the Bioethics Committee of the Medical University of Warsaw.

The levels of gonadal hormones: estradiol, progesterone, follicle-stimulating hormone (FSH), luteinizing hormone (LH), testosterone and dehydroepiandrosterone (DHEA) were measured in the luteal phase, between day 21 and 23 of the cycle.

History of CAD risk factors such as hyperlipidemia, arterial hypertension, smoking, family history, low physical activity was collected. Group I women reported on the life style and risk factors before MI.

e-mail: krzysztofjankowski@hotmail.com

Abbreviations: BMI, body mass index; $C A D$, coronary artery disease; $\mathrm{CH}$, cholesterol; DHEA, dehydroepiandrosterone; $\mathrm{FSH}$, folliclestimulating hormone; $\mathrm{LH}$, luteinizing hormone testosterone; $\mathrm{MI}$, myocardial infarction; TG, triglycerides 
Table 1. Incidence of selected CAD risk factors prior to $\mathrm{MI}$ in group I and group II

\begin{tabular}{|c|c|c|c|c|}
\hline \multicolumn{2}{|c|}{ CAD risk factors } & Group I n= $65(\%)$ & Group II n=30 (\%) & $p$ \\
\hline \multicolumn{2}{|c|}{ Arterial hypertension } & $20(30.7)$ & 0 & - \\
\hline \multicolumn{2}{|c|}{ Hyperlipidemia } & $22(33.8)$ & 0 & - \\
\hline \multicolumn{2}{|c|}{ Diabetes mellitus } & 0 & 0 & - \\
\hline \multicolumn{2}{|c|}{ Cigarette smoking } & 55 (84.6) & $13(43.3)$ & $p<0.001$ \\
\hline \multirow[t]{4}{*}{ BMI $\left(\mathrm{kg} / \mathrm{m}^{2}\right)$} & mean \pm S.D. (range) & $25.9 \pm 3.1(17.1-32.5)$ & $22.8 \pm 2.9(16.9-31.9)$ & $p<0.001$ \\
\hline & $18.5-24.9$ & $19(29.2)$ & $15(50)$ & NS* \\
\hline & $25-29.9$ & $14(21.5)$ & $11(36.7)$ & NS \\
\hline & $\geq 30$ & $32(49.2)$ & $4(13.3)$ & $p<0.01$ \\
\hline \multicolumn{2}{|c|}{ Family history of CAD } & $35(53.8)$ & $6(20)$ & $p<0.01$ \\
\hline \multicolumn{2}{|c|}{ Sedentary life style } & 29 (44.6) & $11(36.7)$ & NS \\
\hline
\end{tabular}

The diagnosis of hypertension was established when the measured arterial pressure values exceeded 140/90 $\mathrm{mmHg}$. Values for lipid measurements were considered pathological for: total cholesterol $(\mathrm{CH}-\mathrm{T})>190$ $\mathrm{mg} / \mathrm{dl}$, LDL cholesterol (LDL-CH) $>115 \mathrm{mg} / \mathrm{dl}$, HDL cholesterol (HDL-CH) $<45 \mathrm{mg} / \mathrm{dl}$, triglycerides (TG) $>150 \mathrm{mg} / \mathrm{dl}$. BMI was calculated for every participant. Obesity was diagnosed in women with BMI $>30 \mathrm{~kg} / \mathrm{m}^{2}$.

Physical activity was assessed according to the WHO MONICA protocol. Low physical activity was recognized when a physical effort of at least $30 \mathrm{~min}$ utes was performed less than twice a week. A sedentary type of work was performed by those women who spent more than $50 \%$ of working time sitting (WHO Monica Project, 1987).

Hormone levels were estimated using fluoroimmunometric methods (TR-FIA) using kits by Delfia (Farmacia LKB, Finland). Lipid concentrations were estimated by the use of common commercial kits. Patients from group I had the statin treatment withheld for 2 weeks before the blood draw. The treatment was resumed immediately after the blood draw.

Table 2. Sex hormone levels in groups I and II

\begin{tabular}{|c|c|c|c|c|}
\hline Hormone & & Group I $(n=65)$ & Group II $(n=30)$ & $p$ \\
\hline \multirow[b]{2}{*}{ Estradiol (nmol/l) } & range & $0.11-1.2$ & $0.15-0.41$ & \multirow[b]{2}{*}{ NS* } \\
\hline & mean \pm S.D. & $0.31 \pm 0.22$ & $0.31 \pm 0.11$ & \\
\hline \multirow{2}{*}{$\begin{array}{l}\text { Progesterone } \\
(\mathrm{nmol} / \mathrm{l})\end{array}$} & range & $5.2-61.0$ & $7.5-67.0$ & \multirow{2}{*}{ NS } \\
\hline & mean \pm S.D. & $22.15 \pm 16.86$ & $27.02 \pm 17.74$ & \\
\hline \multirow{2}{*}{$\begin{array}{l}\mathrm{FSH} \\
(\mathrm{ng} / \mathrm{ml})\end{array}$} & range & $0.1-2.7$ & $0.5-3.8$ & \multirow{2}{*}{ NS } \\
\hline & mean \pm S.D. & $1.54 \pm 0.77$ & $1.82 \pm 1.44$ & \\
\hline \multirow{2}{*}{$\begin{array}{l}\text { LH } \\
(\mathrm{ng} / \mathrm{ml})\end{array}$} & range & $0.2-3.0$ & $0.2-4.3$ & \multirow{2}{*}{ NS } \\
\hline & Mean \pm S.D. & $1.19 \pm 1.02$ & $0.99 \pm 0.91$ & \\
\hline \multirow{2}{*}{$\begin{array}{l}\text { Testosteron } \\
(\mathrm{nmol} / \mathrm{l})\end{array}$} & range & $0.4-4.5$ & $0.2-4.1$ & \multirow{2}{*}{ NS } \\
\hline & mean \pm S.D. & $2.02 \pm 1.07$ & $1.68 \pm 0.96$ & \\
\hline \multirow{2}{*}{$\mathrm{DHEA}(\mu \mathrm{mol} / \mathrm{l})$} & range & $0.6-2.7$ & $0.5-2.7$ & \multirow{2}{*}{ NS } \\
\hline & mean \pm S.D. & $1.49 \pm 0.65$ & $1.46 \pm 0.65$ & \\
\hline
\end{tabular}

*not significant
Mean levels of hormones were compared between the group of post MI women and the control group. In the first group an analysis was performed comparing mean levels of gonadal hormones in patients with the presence of CAD risk factors with the levels in patients without the risk factor.

For statistical analysis Statistica software was used. The differences between the analyzed parameters were estimated using non-parametric tests $\mathrm{Chi}^{2}$ and Fischer exact test. The obtained differences were assumed statistically significant for $p<0.05$.

\section{RESULTS}

Table 1 presents the incidence of classic CAD risk factors in both examined groups.

Smoking was significantly more common in the group of post MI women, as was the incidence of obesity and a positive family history. A trend towards a higher proportion of women with low physical activity was observed, but it did not reach statistical significance. In the control group there were no women with arterial hypertension or hormonal abnormalities, while these risk factors were present in $30 \%$ of the post MI group.

All examined women had normal mean levels of gonadal hormones (Table 2).

The values of lipid parameters are presented in Table 3.

In the group of women post MI (group I), a relationship between hormone concentrations and selected CAD risk factors, such as arterial hypertension, hyperlipidemia, cigarette smoking, obesity, CAD family history, sedentary way of living was analyzed (Tables 4-6).

In the group of examined post MI women there were no significant differences in the mean concentrations of estradiol, FSH, LH and DHEA. 
Table 3. Lipid parameters in group I and II

\begin{tabular}{|c|c|c|c|c|}
\hline Lipid parameters (mg/dl) & & Group I $(n=60)$ & Group II $(n=30)$ & $p$ \\
\hline \multirow[t]{2}{*}{$\mathrm{CH}-\mathrm{T}$} & range & $160-349$ & $142-237$ & $p<0.0001$ \\
\hline & mean \pm S.D. & $243.62 \pm 46.32$ & $195.87 \pm 22.93$ & \\
\hline \multirow[t]{2}{*}{ LDL-CH } & range & $71-263$ & $82-174$ & $p<0.0001$ \\
\hline & mean \pm S.D. & $167.63 \pm 43.88$ & $123.39 \pm 25.07$ & \\
\hline \multirow[t]{2}{*}{$\mathrm{HDL}-\mathrm{CH}$} & range & $27-86$ & $37-82.0$ & $p<0.01$ \\
\hline & mean \pm S.D. & $47.61 \pm 11.27$ & $58.87 \pm 13.27$ & \\
\hline \multirow[t]{2}{*}{ TG } & range & $60-352$ & $37-108$ & $p<0.01$ \\
\hline & mean \pm S.D. & $141.58 \pm 62.41$ & $70.87 \pm 18.77$ & \\
\hline
\end{tabular}

However, in the post MI patients leading a sedentary life style, a significantly lower mean progesterone concentration was observed $(16.29 \pm 9.11$ versus $29.43 \pm 21.14$ $\mathrm{nmol} / 1, p<0.05)$ and significantly higher mean testosterone concentration $(2.34 \pm 0.98$ versus $1.76 \pm 1.09 \mathrm{nmol} / 1$, $p<0.05)$ when compared to patients from the same group, but leading a more active life. In the control group lower progesterone levels were observed in women with low physical activity, but the difference was not statistically significant. There was no difference in testosterone levels between physically and non-active women in group II. In obese post MI women (BMI $\geq 30 \mathrm{~kg} /$ $\left.\mathrm{m}^{2}\right)$ a lower mean concentration of progesterone was detected (18.02 \pm 8.12 versus $26.16 \pm 14.72 \mathrm{nmol} / 1, p<0.05)$ when compared to slimmer $\left(B M I<30 \mathrm{~kg} / \mathrm{m}^{2}\right)$ patients from the same group. In group II this difference was not statistically significant. In post MI women with positive family history for CAD, a significantly higher mean concentration of testosterone was detected $(2.31 \pm 1.22$ versus $1.67 \pm 0.74 \mathrm{nmol} / 1, p<0.05)$ than in patients with no family history. In the control group a trend towards higher values of testosterone was seen among women with positive family history for coronary artery disease, but it was not statistically significant.

\section{DISCUSSION}

The higher risk of symptomatic CAD in postmenopausal versus premenopausal women suggests a protective effect of endogenous female gonadal hormones. Estrogens are known to modify the levels of lipid fractions, retarding the development of atherosclerotic plaques, ameliorating endothelial function and stimulating the synthesis of nitric oxide. In experimental models estrogen relaxes the endothelin-induced vessel contraction, augments the synthesis of prostacyclin in smooth muscle cell cultures and possibly directly inhibits calcium channels causing vessel relaxation (Rosano et al., 1993; Mendelsohn \& Karas, 1999; Binko \& Majewski, 1998). The estrogens reduce inflammatory state via modulation of expression of adhesion molecules, they also participate in myocardial protection (ischemic preconditioning). Klosiewicz-Wasek et al. (2008) described a negative correlation between the concentration of endogenous estrogens and the thickness of intima-media complex in premenopausal women (Caulin-Glaser, 1998; Lee et al., 2002; Tsun Ming et al., 2003). Progesteron reduces the anti-atherogenic effect of estrogens on lipid metabolism via impairment of lipoprotein lipase activity and stimulation of hepatic lipase activity. On the other hand, it has been demonstrated that progesterone inhibits migration of macrophages and slows down intracellular lipid turn-over, thus exerting atheroprotective effects (Mc Crohon et al., 1999). Both hormones inhibit smooth muscle cell proliferation and relax coronary vessels via calcium channel inhibition (Lee et al., 1997).

Table 4. Relationship between estradiol ( $\mathrm{nmol} / \mathrm{l})$ and progesterone $(\mathrm{nmol} / \mathrm{l})$ concentrations and the presence of CAD risk factors

\begin{tabular}{|c|c|c|c|}
\hline \multicolumn{4}{|c|}{ Estradiol (mean \pm S.D.) } \\
\hline Risk factor & Patients with the risk factor & Patients without the risk factor & $p$ \\
\hline 1. & 2. & 3. & 4. \\
\hline Arterial hypertension $\mathrm{n}(\%)$ & $0.31 \pm 0.20 ; 20(30.8)$ & $0.2 \pm 0.27 ; 45(69.2)$ & $\mathrm{NS}^{*}$ \\
\hline Hyperlipidemia n (\%) & $0.9 \pm 0.18 ; 55$ (84.6) & $0.33 \pm 0.18 ; 10(15.4)$ & NS \\
\hline Cigarette smoking n (\%) & $0.24 \pm 0.20 ; 55(84.6)$ & $0.32 \pm 0.22 ; 10(15.4)$ & NS \\
\hline Obesity n (\%) & $0.32 \pm 0.21 ; 31(47.7)$ & $0.29 \pm 0.23 ; 34(52.3)$ & NS \\
\hline CAD family history $n$ (\%) & $0.31 \pm 0.16 ; 35(53.8)$ & $0.31 \pm 0.26 ; 30(46.2)$ & NS \\
\hline Sedentary life style n (\%) & $0.28 \pm 0.22 ; 29(44.6)$ & $0.34 \pm 0.22 ; 36(55.4)$ & NS \\
\hline \multicolumn{4}{|c|}{ Progesterone (mean \pm S.D.) } \\
\hline 1. & 2. & 3. & 4. \\
\hline Arterial hypertension $\mathrm{n}(\%)$ & $23.48 \pm 9.12 ; 20(30.8)$ & $19.16 \pm 10.79 ; 45(69.2)$ & NS \\
\hline Hyperlipidemia n (\%) & $19.51 \pm 7.57 ; 55(84.6)$ & $23.12 \pm 9.17 ; 10(15.4)$ & NS \\
\hline Cigarette smoking n (\%) & $16.72 \pm 8.21 ; 55(84.6)$ & $23.14 \pm 15.31 ; 10(15.4)$ & NS \\
\hline Obesity n (\%) & $18.02 \pm 8.12 ; 31(47.7)$ & $26.16 \pm 14.72 ; 34(52.3)$ & $p<0.05$ \\
\hline CAD family history $\mathrm{n}(\%)$ & $21.63 \pm 13.73 ; 35(53.8)$ & $22.59 \pm 11.63 ; 30(46.2)$ & NS \\
\hline Sedentary life style n (\%) & $16.29 \pm 9.11 ; 29(44.6)$ & $29.43 \pm 21.14 ; 36(55.4)$ & $p<0.01$ \\
\hline
\end{tabular}

*not significant 
Table 5. Relationship between FSH ( $\mathrm{ng} / \mathrm{ml})$ and $\mathrm{LH}(\mathrm{ng} / \mathrm{ml})$ concentrations and the presence of CAD risk factors

\begin{tabular}{|c|c|c|c|}
\hline \multicolumn{4}{|c|}{ FSH (ng/ml) (mean \pm S.D.) } \\
\hline Risk factor & Patients with the risk factor & Patients without the risk factor & $p$ \\
\hline 1. & 2. & 3. & 4. \\
\hline Arterial hypertension n (\%) & $1.59 \pm 0.80 ; 20(30.8)$ & $1.44 \pm 0.73 ; 45(69.2)$ & $N S^{*}$ \\
\hline Hyperlipidemia n (\%) & $1.48 \pm 0.49 ; 55(84.6)$ & $1.77 \pm 0.71 ; 10(15.4)$ & NS \\
\hline Cigarette smoking n (\%) & $1.91 \pm 0.59 ; 55(84.6)$ & $1.48 \pm 0.79 ; 10(15.4)$ & NS \\
\hline Obesity n (\%) & $1.46 \pm 0.87 ; 31(47.7)$ & $1.62 \pm 0.67 ; 34(52.3$ & NS \\
\hline CAD family history $n(\%)$ & $1.52 \pm 0.78 ; 35(53.8)$ & $1.57 \pm 0.78 ; 30(46.2)$ & NS \\
\hline Sedentary life style n (\%) & $1.58 \pm 0.76 ; 29(44.6)$ & $1.50 \pm 0.81 ; 36(55.5)$ & NS \\
\hline \multicolumn{4}{|c|}{ LH (ng/ml ) (mean \pm S.D.) } \\
\hline 1. & 2. & 3. & 4. \\
\hline Arterial hypertension n (\%) & $1.23 \pm 1.08 ; 20(30.8)$ & $1.12 \pm 0.90 ; 45(69.2)$ & NS \\
\hline Hyperlipidemia n (\%) & $0.99 \pm 1.07 ; 55(84.6)$ & $1.31 \pm 0.87 ; 10(15.4)$ & NS \\
\hline Cigarette smoking n (\%) & $0.94 \pm 0.87 ; 55(84.6)$ & $1.24 \pm 1.04 ; 10(15.4)$ & NS \\
\hline Obesity n (\%) & $1.21 \pm 0.94 ; 31$ (49.77) & $1.17 \pm 1.11 ; 34(52.3)$ & NS \\
\hline CAD family history $\mathrm{n}(\%)$ & $1.07 \pm 0.93 ; 35(53.8)$ & $1.30 \pm 1.09 ; 30(46.2)$ & NS \\
\hline Sedentary life style n (\%) & $1.36 \pm 0.76 ; 29(44.6)$ & $0.99 \pm 0.77 ; 36(54.4)$ & NS \\
\hline
\end{tabular}

*not sagnificant

In the post MI patients we observed significantly lower levels of progesterone in the subgroup of obese women and those with low physical activity, than in women with no such risk factors. Low physical activity is considered one of the four most important factors influencing the development of atherosclerosis, and high physical activity protects from cardiovascular diseases (Berlin \& Colditz, 1990; Wenger et al., 1998; Yusuf et al., 2004). Low physical activity is very often linked to other risk factors, as it predisposes to obesity, diabetes and elevated arterial pressure. Even a small gain in body weight, independent of physical activity, is linked to higher mortality rate in women. With BMI values exceeding $25 \mathrm{~kg} /$ $\mathrm{m}^{2}$ and physical activity lower than 3.5 hours per week, overweight is responsible for $59 \%$ of cardiovascular deaths (Hu et al., 2004).

There are no data in the literature on the role of lower progesterone levels in the group of obese women or women with low physical activity. Klos et al. (2001) have demonstrated lower levels of progesterone in the luteal phase in 44 post MI women, especially those smoking. Mauvais-Jarvis et al. (1983) showed that progesterone exerts an antagonistic

Table 6. Relationship between concentrations of testosterone $(\mathrm{nmol} / \mathrm{l})$ and DHEA $(\mu \mathrm{mol} / \mathrm{l})$ and the presence of risk factors

\begin{tabular}{|c|c|c|c|}
\hline \multicolumn{4}{|c|}{ Testosterone $(\mathrm{nmol} / \mathrm{l})($ mean \pm S.D. $)$} \\
\hline Risk factor & Patients with the risk factor & Patients without the risk factor & $p$ \\
\hline 1. & 2. & 3. & 4. \\
\hline Arterial hypertension $\mathrm{n}(\%)$ & $2.02 \pm 1.02 ; 20(30.8)$ & $2.00 \pm 1.20 ; 45(69.2)$ & $\mathrm{NS}^{*}$ \\
\hline Hyperlipidemia n (\%) & $2.01 \pm 1.01 ; 55(84.6)$ & $2.00 \pm 1.19 ; 10(15.4)$ & NS \\
\hline Cigarette smoking n (\%) & $1.72 \pm 0.54 ; 55(84.6)$ & $2.02 \pm 1.13 ; 10(15.4)$ & NS \\
\hline Obesity n (\%) & $2.17 \pm 1.18 ; 31(47.7)$ & $1.87 \pm 0.93 ; 34(52.3)$ & NS \\
\hline CAD family history $\mathrm{n}(\%)$ & $2.31 \pm 1.22 ; 35(53.8)$ & $1.67 \pm 0.74 ; 30(46.2)$ & $p<0.05$ \\
\hline Sedentary life style $n(\%)$ & $2.34 \pm 0.98 ; 29(44.6)$ & $1.76 \pm 1.09 ; 36(55.4)$ & $p<0.05$ \\
\hline \multicolumn{4}{|c|}{ DHEA $(\mu \mathrm{mol} / \mathrm{l})(\mathrm{mean} \pm$ S.D. $)$} \\
\hline 1. & 2. & 3. & 4. \\
\hline Arterial hypertension $\mathrm{n}(\%)$ & $1.47 \pm 0.60 ; 20(30.8)$ & $1.51 \pm 0.76 ; 45(69.2)$ & NS \\
\hline Hyperlipidemia n (\%) & $1.46 \pm 0.59 ; 55(84.6)$ & $1.52 \pm 0.67 ; 10(15.4)$ & NS \\
\hline Cigarette smoking n (\%) & $1.39 \pm 0.65 ; 55(84.6)$ & $1.51 \pm 0.65 ; 10(15.4)$ & NS \\
\hline Obesity n (\%) & $1.60 \pm 0.61 ; 31(47.7)$ & $1.38 \pm 0.68 ; 34(52.3)$ & NS \\
\hline CAD family history $\mathrm{n}(\%)$ & $1.36 \pm 0.58 ; 35(53.8)$ & $1.61 \pm 0.69 ; 30(46.2)$ & NS \\
\hline Sedentary life style $\mathrm{n}(\%)$ & $1.44 \pm 0.70 ; 29(44.6)$ & $1.56 \pm 0.58 ;(55.4)$ & NS \\
\hline
\end{tabular}

*not sagnificant 
effect to mineralocorticoids. It is possible that progesterone deficiency in obese women promotes the proatherogenic effect of aldosterone.

In the examined group of young women post MI a higher mean value of testosterone was detected in the subgroup of women with low physical activity and those with positive family history of CAD in comparison to women without these risk factors. The proatherogenic effect of testosterone in women has been known for a long time, however, testosterone concentrations in women are rarely a subject of clinical research, not to mention routine examination. Women with polycystic ovaries syndrome are an exception, but they were not included in our study (Dahlgren et al., 1992; Talbott et al., 2008). Testosterone may raise the risk of MI by stimulation of platelet aggregation via activation of tromboxane A2 or by lowering the plasma fibrinolytic activity (Adesuyi et al., 1995; Weksler et al., 2002). This would be of particular importance in young women, who often experience MI with no significant atherosclerotic lesions in coronary arteries. There is no data in the literature on a link of testosterone level and family history of CAD. Such a linkage could be due to the atherogenic properties of testosterone. Seliger et al. (2003) have demonstrated higher platelet activity in young women $<48$ years old with positive family history of CAD in comparison to older women.

In the literature we found no data on the relationship between elevated levels of testosterone and low physical activity. In group of men post myocardial infarction Wranicz et al. (2003) described a positive correlation between testosterone levels and increased activity of sympathetic nervous system. It is possible that in a similar way the relationship between an elevated testosterone level and the dominance of sympathetic nervous system in group of women with low physical activity may be explained.

The results of our study suggest a significant relation between levels of gonadal hormones and classical CAD risk factors.

\section{Study limitations}

The study limitation is relatively small group size. Also results of coronary angiography and the extend of atherosclerotic lesions of coronary arteries would be undoubtedly a strong asset of the study, however, more than $30 \%$ of examined women had no angiography performed and we could not obtain complete angiography protocol in a few of remaining patients.

\section{REFERENCES}

Adesuyi AL, Ajayi AAL, Mathur R, Halushka PV (1995) Testosterone increases human platelet thromboxane A2 receptor density and aggregation responses. Circulation 91: 2742-2747.

Arciero TJ, Jacobsen SJ, Reeder GS, Frye RL, Weston SA, Killian JM, Roger Vr VL (2004) Temporal trends in the incidence of coronary disease. Am J Med 117: 228-233.

Berlin JA, Colditz GA (1990) A meta-analysis of physical activity in prevention of coronary heart disease. Am J Epidemiol 132: 612-628.

Binko J, Majewski H (1998) 17 B-estradiol reduces vasoconstriction in endothelium denuded rat aortas through inducible NOS. Am J Physiol 274: H853-H859.
Broda G (2000) The epidemiology of cardiovascular diseases in women. Kardiol Pol 52: III-6 (in Polish).

Caulin-Glaser T (1998) Modulation of circulating cellular adhesion molecules in postmenopausal women with coronary artery disease. J Am Coll Cardiol 3: 1555-1559.

Dahlgren E, Janson PO, Johansson S, Lapidus L, Odén A (1992) Polycystic ovary syndrome and risk for myocardial infarction: evaluated from a risk factor model based on a prospective population study of women. Acta Obstet Gynecol Scand 71: 599-604.

Doughty M, Mehta R, Bruckman D, Das S, Karavite D, Tsai T, Eagle $K$ (2002) Acute myocardial infarction in the young. The Univeristy of Michigan experience. Am Heart J 143: 56-62.

Ergin A, Muntner P, Sherwin R, He J (2004) Secular trends in cardiovascular disease mortality, incidence, and case fatality rates in adults in the United States. Am I Med 117: 217-227.

Hu FB, Willett WC, Li T, Stampfer MJ, Colditz GA, Manson JE (2004) Adiposity as compared with physical activity in predicting mortality among women. $N$ Engl J Med 351: 2694-2703.

Klos J, Ceremuzyński L., Herbaczynska-Cedro K (2001) Lowered levels of gonadal hormones in women with premenopausal ischemic heart disease. Influence of cigarette smoking. Kardiol Pol 55: 305307 (in Polish).

Klosiewicz-Wasek B, Ceremuzynski L, Polonski L, Lukaszewicz R, Wasilewski J (2008) Association between carotid artery atherosclerosis and coronary artery disease in young females. Reference to sex hormone profile. Kardiol Pol 66: 127-132; discussion 66: 133-134 (in Polish).

Lee TM, Su SF, Chou T, Tsai CH (2002) Pharmacological preconditioning of estrogen by activation of myocardial adenosine triphosphate-sensitive potassium channels in patients undergoing coronary angioplasty. J Am Coll Cardiol 39: 871-877.

Lee WS, Harder JA, Yoshizumi M, Lee ME, Haber E (1997) Progesterone inhibits arterial smooth muscle cell proliferation. Nat Med 3: 1005-1008.

Mauvais-Jarvis P (1983) Progesterone and progestins: a general overview. In Progesterone and Progestins. Bardin WC, Milgrom F, MauvaisJarvis P eds, p 1, Raven Press, New York.

Mc Crohon JA, Nakhla S, Jessup W, Stanley KK, Celermajer DS (1999) Estrogen and progesterone reduce lipid accumulation in human monocyte-derived macrophages. A sex-specific effect. Circulation 100: 2319-2325.

Mendelsohn ME, Karas RH (1999) The protective effects of estrogen on the cardiovascular system. N Engl J Med 23: 1801-1881.

Ostadal B, Netuka I, Maly J, Besik J, Ostadalova I (2009) Gender differences in cardiac ischemic injury and protection - experimental aspects. Exp Biol Med 234: 1011-1019.

Rosano GMC, Sarrel PM, Wilson PA, Collins P (1993) Beneficial effect of estrogen on exercise-induced myocardial ischaemia in women with coronary artery disease. Lancet 342: 133-136.

Seliger SL, Easterling TR, Gillen FL (2003) Platelet hyperreactivity in women from families with premature atherosclerosis. $\mathrm{Am} \mathrm{Med}$ Women's Assoc 58: 4 (abstract).

Smielak-Korombel W, Kulon I, Franaszek J, Kanas P (1986) Myocardial infarction in women to 45 years of age. Pol Tyg Lek 36: 11311133 (in Polish).

Talbott EO, Zborowski J, Reger J, Stragand IR (2008) Is there independent effect of polycystic ovary syndrome (PCOS) and menopause on the prevalence of subclinical atherosclerosis in middle aged women? Vasc Health Risk Manag 4: 453-462.

Tsun Ming L, Tai-Fwu T, Chanher T (2003) Differential role of KATP channels activated by conjugated estrogens in the regulation of myocardial and coronary protective effects. Circulation 107: 49-54.

Weksler B (2002) Hemostasis and thrombosis. In: Cardiovascular health and disease in women. 2nd edn, pp 157-177, Douglas PS ed, WB Saunders, Philadelphia.

Wenger NK (1998) Coronary heart disease in women. In: Textbook of women's health. Wallis LA, Kasper AS, Reader GG, Barbo DM, Brown W, Etingin OR, Nadelson CC, Pinn VW eds, pp 329-340, Lippincot-Raven Publishers, Philadelphia, New York.

WHO MONICA (1987) Project geographic variation in mortality from cardiovascular diseases. Baseline data on selected population characteristics and cardiovascular mortality. Wld Hlth Statist 40: 171-184.

Wranicz JK, Rosiak M, Cygankiewicz I, Kula P (2003) Sex steroids and heart variability in men with coronary artery disease after myocardial infarction. Pol Arch Med Wewn 109: 157-163 (in Polish).

Yusuf S, Hawken S, Rosengren S (2004) Effect of potentially modifiable risk factors associated with myocardial infarction in 52 countries (the INTERHEART Study): case-control study. Lancet 364: 937-952. 